\title{
INTERPRETASI DEPOSIT URANIUM BERDASARKAN DATA TAHANAN JENIS DAN POLARISASI TERINDUKSI DI SEKTOR RABAU HULU
}

\section{URANIUM DEPOSIT INTERPRETATION BASED ON RESISTIVITY AND INDUCED POLARIZATION DATA IN RABAU HULU SECTOR}

Naskah diterima: 30 Oktober 2015, direvisi: 6 November 2015, disetujui: 10 November 2015

\begin{abstract}
ABSTRAK
Daerah Rabau Hulu, Kalan, Kalimantan Barat merupakan daerah potensial uranium yang telah dieksplorasi secara detil dengan berbagai metode. Metode tahanan jenis dan polarisasi terinduksi dapat diterapkan dalam eksplorasi deposit uranium yang mineralisasinya berasosiasi dengan mineral sulfida. Pengolahan, analisis, dan interpretasi data tahanan jenis dan polarisasi terinduksi dilakukan untuk dapat mengidentifikasi sebaran deposit uranium dan litologi batuan di daerah penelitian. Deposit uranium di daerah Rabau Hulu pada umumnya berasosiasi dengan sulfida, turmalin, dan terdapat dalam batuan favourable. Indikasi mineralisasi uranium dijumpai dalam bentuk-bentuk tidak teratur dan tidak merata yang terdiri atas mineral uraninit, pirit, kalkopirit, pirhotit, molibdenit, dan ilmenit. Pengambilan data menggunakan konfigurasi dipole-dipole pada area sekitar 36 hektare, terdiri atas 46 lintasan dengan panjang $\pm 425 \mathrm{~m}$. Pengambilan data polarisasi terinduksi dalam kawasan frekuensi dengan titik dan lintasan yang sama dengan data tahanan jenis. Pengolahan data menghasilkan nilai tahanan jenis dan faktor logam yang selanjutnya dibuat penampang 2 dimensi. Penentuan nilai tahanan jenis dan polarisasi terinduksi dilakukan dengan mengkorelasi data sumur bor dengan hasil pengolahan data. Tahanan jenis pada zona deposit uranium bernilai kurang dari $2.000 \Omega \mathrm{m}$ dan nilai faktor logamnya lebih besar dari $90 \mathrm{mho} / \mathrm{m}$. Zona deposit uranium ini semakin meluas seiring dengan kedalaman. Distribus deposit uranium berarah barat daya-timur laut dan berbentuk lensa.
\end{abstract}

Kata kunci: deposit uranium, tahanan jenis, polarisasi terinduksi, Rabau Hulu

\section{ABSTRACT}

Rabau Hulu area, Kalan, Kalimantan Barat is a potential area of uranium that has been explored in detail by various methods. Methods of resistivity and induced polarization can be applied in the exploration of uranium deposits in which its mineralization associated with sulphide minerals. Processing, analysis, and interpretation of resistivity and induced 
polarization data conducted in order to identify the distribution of uranium deposits and lithology of the rocks in the study area. Uranium deposits in the area Rabau Hulu is generally associated with sulphides, tourmaline and contained in favorable rocks. Symptoms of uranium mineralization encountered in other forms of irregular and uneven consists of uraninite, pyrite, chalcopyrite, pyrrhotite, molybdenite, and ilmenite minerals. Data acquisition using dipoledipole configuration in an area of approximately 36 hectares, 46 lines along $\pm 425 \mathrm{~m}$. Acquisition of induced polarization frequency domain data which the same points and lines with resistivity data. Data processing produces resistivity and metal factor values and subsequently made two-dimensional section. Determination of resistivity and induced polarization are done by correlated boreholes data with the results of data processing. Resistivity of uranium deposits zone worth less than 2,000 $\mathrm{Sm}$ and the value of metal factor greater than $90 \mathrm{mho} / \mathrm{m}$. Uranium deposit zone is expanding along with the depth. Uranium deposits distribution trending Southwestern-Northeast and shaped lens.

Keywords: uranium deposit, resistivity, induced polarization, Rabau Hulu

\section{PENDAHULUAN}

Menurut IAEA ${ }^{[1]}$, diperkirakan akan terjadi defisit antara produksi dari cadangan yang telah diketahui dengan kebutuhan akan uranium pada tahun 2026 (kebutuhan tinggi) atau defisit akan terjadi pada tahun 2035 (kebutuhan menengah). Hal ini dapat diimbangi dengan ditemukannya cadangan uranium baru serta penemuan teknologi baru yang meningkatkan efisiensi penggunaan uranium. Peningkatan cadangan dapat dilakukan dengan melakukan evaluasi kembali terhadap daerah potensial mengandung uranium. Salah satu daerah di Kalan yang berpotensi dan akan dilakukan evaluasi kembali adalah sektor Rabau Hulu (Gambar $1^{[2]}$ ).

Geomorfologi daerah Rabau Hulu merupakan daerah berbukit terjal, berarah barat daya-timur laut dengan elevasi sekitar 450 - $600 \mathrm{~m}$ dan kemiringan lereng berkisar $45^{\circ}$ sampai subvertikal ${ }^{[3]}$. Secara stratigrafi, daerah Rabau Hulu merupakan bagian tengah (intermediate serie) dari Cekungan Kalan yang terdiri dari kuarsit mikro muskovit, kuarsit mikro biotit, kuarsit muskovit, kuarsit leopard, serta terobosan granit dan greisen. Pola penyebaran litologi/stratifikasi secara umum berarah timur laut-barat daya dengan kemiringan $30-40^{\circ}$ ke utara $^{[4,5]}$.

Secara regional, granit Sukadana di Pegunungan Schwaner yang berumur Kapur Atas (91 - 80 juta tahun yang lalu) merupakan pembawa elemen radioaktif dengan ditunjukkan adanya elemen $\mathrm{U}$ dan Th. Mineral radioaktif yang terdapat pada granit menunjukkan bahwa pembentukan mineral uranium berkaitan dengan granit Sukadana berumur Kapur Atas. Batuan granit tersebut diduga sebagai pembawa mineral uranium dan terjadi pada post metamorfik ${ }^{[6]}$.

Indikasi mineralisasi uranium yang ditemukan di Rabau Hulu dapat dibedakan menjadi dua tipe, yaitu terakumulasi dalam bidang tektonik dan terakumulasi dalam pori di antara mineral. Mineral terakumulasi dalam bidang tektonik mengisi bidang frakturasi, berbentuk urat dengan ketebalan milimetrik - sentimetrik, dan tersebar tidak merata. Bidang mineralisasi secara umum berarah $\mathrm{N} 70^{\circ} \mathrm{E}-\mathrm{N} 80^{\circ} \mathrm{E}$ dengan kemiringan ke utara. Sedangkan mineralisasi dalam pori 
batuan mengisi ruang antar mineral, pengolahan kembali data yang diambil tahun berbentuk nodul-nodul ${ }^{[6]}$. Gejala mineralisasi uranium dijumpai dalam bentuk-bentuk tidak teratur dan tidak merata. Mineral radioaktif berupa uraninit berasosiasi dengan ilmenit, magnetit, pirhotit, pirit, molibdenit, spalerit, lolingit, bornit, kalkopirit, dan turmalin ${ }^{[4]}$.

Penelitian ini dimaksudkan untuk dapat menentukan pola sebaran lateral deposit uranium berdasarkan hasil pengolahan data tahanan jenis dan polarisasi terinduksi di daerah Rabau Hulu, Kalan, Kalimantan Barat. Fokus penelitaian ini adalah melakukan

1985.

Pengolahan dan pemodelan data terdahulu masih dilakukan secara manual berdasarkan data lapangan. Hal ini karena masih terbatasnya perangkat lunak maupun perangkat keras komputer untuk mengolah data yang telah diperoleh. Oleh karena itu, perlu dilakukan kembali pengolahan data yang didukung oleh perangkat lunak yang telah ada saat ini. Hasil pengolahan yang diperoleh saat ini diharapkan dapat lebih menggambarkan kondisi bawah permukaan yang mendekati keadaan sebenarnya.

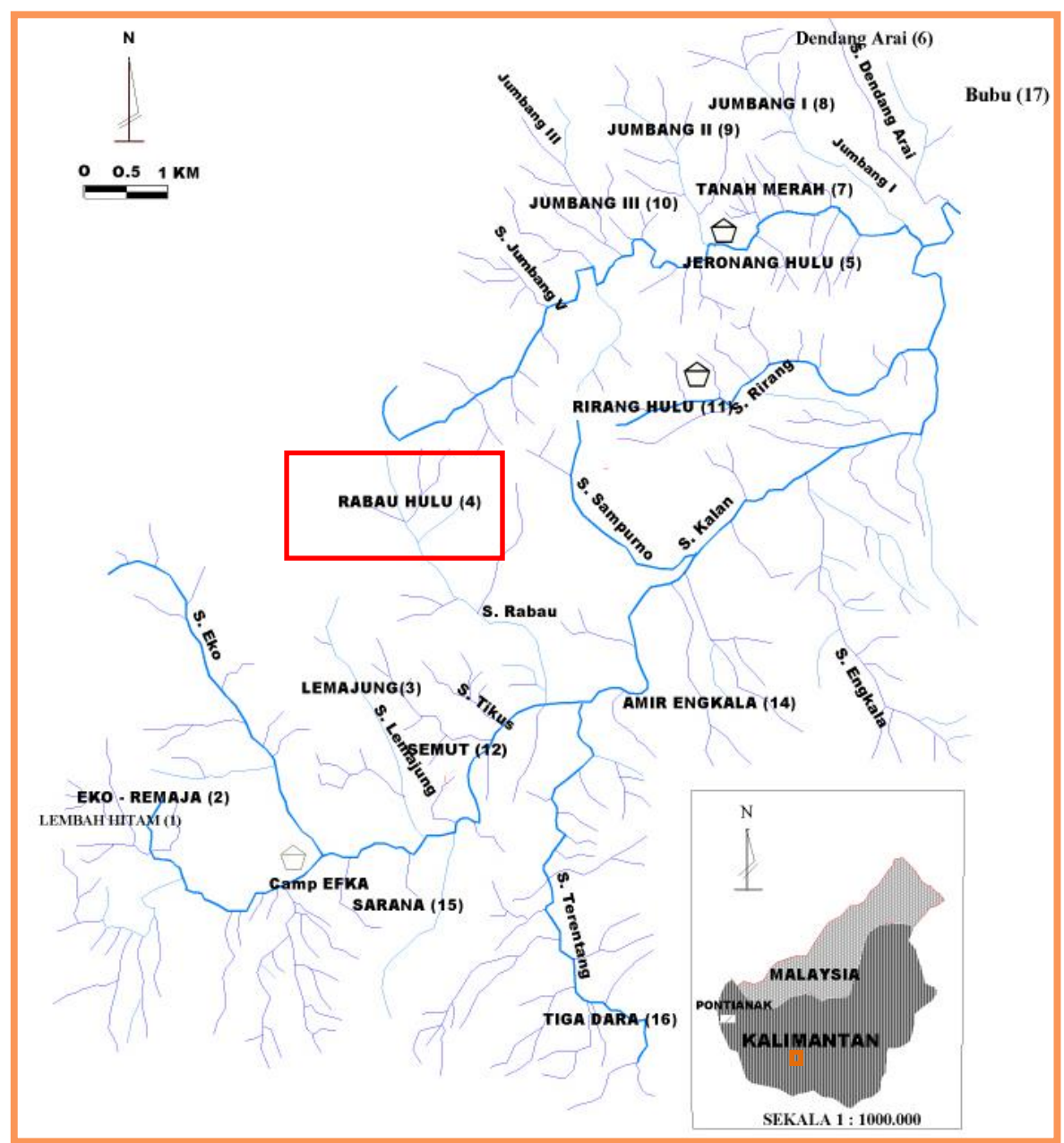

Gambar 1. Daerah penelitian di sektor Rabau Hulu, Kalan, Kalimantan Barat ${ }^{[2]}$. 


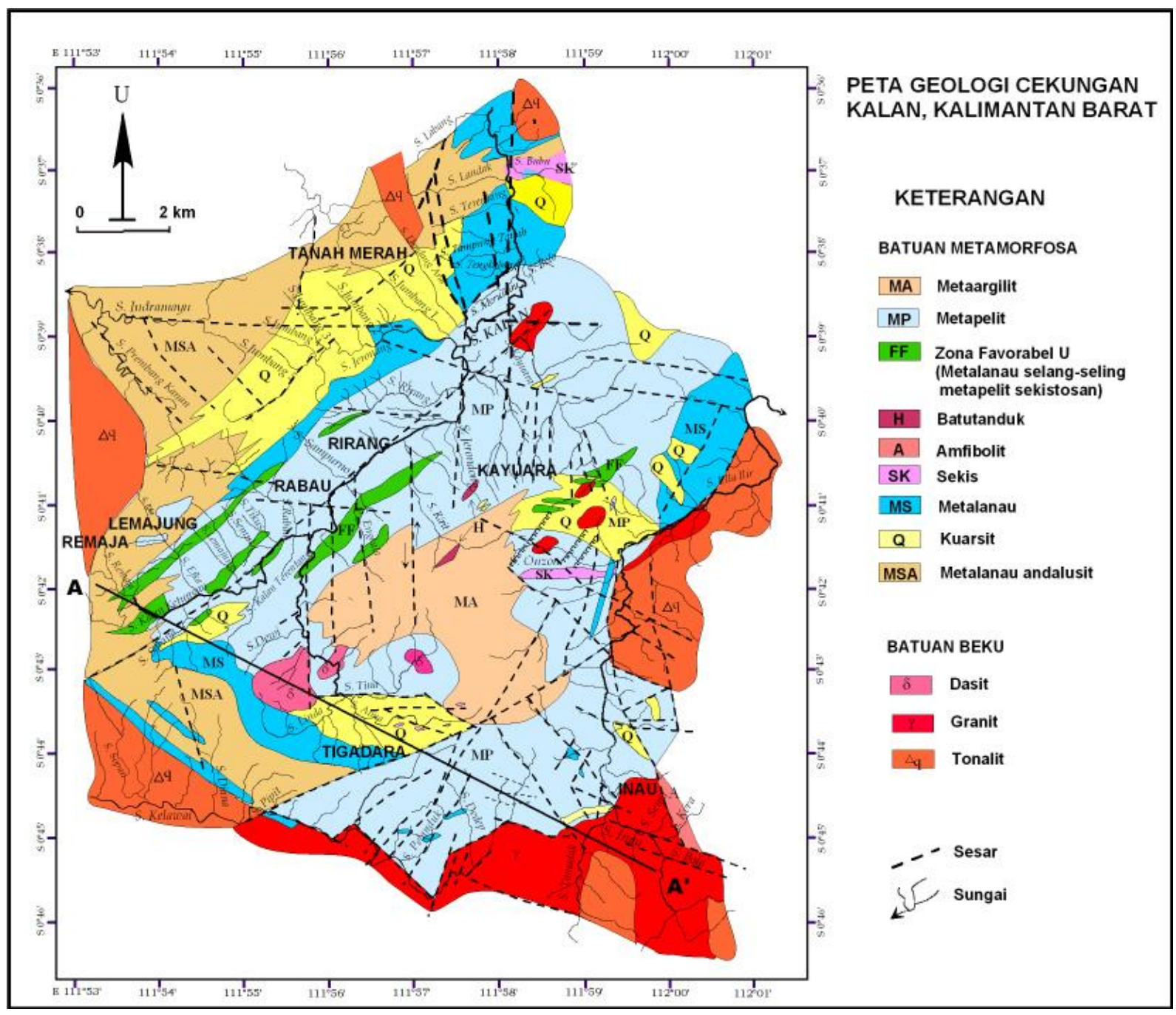

Gambar 2. Peta Geologi Cekungan Kalan ${ }^{[5]}$.

Mineral sulfida adalah sumber dari respon polarisasi terinduksi. Dengan demikian, bila dikombinasikan dengan data lubang bor, model chargeability dapat digunakan untuk memperkirakan jumlah dan distribusi sulfida ${ }^{[7]}$. Mineral yang berasosiasi dengan deposit uranium terdiri atas mineral logam dan mineral sulfida. Mineral logam terdiri atas ilmenit, magnetit, dan pirhotit. Mineral sulfida terdiri atas pirit, molibdenit, spalerit, bornit, dan kalkopirit. Mineral asosiasi inilah yang menjadi target survei tahanan jenis dan polarisasi terinduksi. Mineral-mineral tersebut digunakan sebagai acuan dalam menentukan keberadaan deposit uranium.

\section{TEORI}

\section{Metode Tahanan Jenis}

Metode tahanan jenis merupakan metode geofisika yang digunakan untuk menyelidiki kondisi bawah permukaan dengan memanfaatkan sifat kelistrikan batuan. Besaran yang diukur pada metode tahanan jenis adalah perbedaan potensial listrik dan kuat arus listrik sehingga nilai tahanan jenisnya dapat dihitung. Hukum Ohm menyatakan bahwa beda potensial akibat suatu beban $(\Delta \mathrm{V})$ berbanding lurus dengan arus listrik (I) yang ditunjukkan oleh persamaan $1^{[8]}$ :

$$
\Delta V=I R
$$


dimana $\mathrm{R}$ adalah resistansi atau tahanan listriknya.

Konsep dasar pengukuran tahanan jenis batuan dimodifikasikan dari pengukuran tahanan jenis suatu sampel bahan di laboratorium yang skemanya diberikan oleh Gambar 3 dan tahanan jenisnya didefinisikan oleh persamaan $2^{[8]}$ :

$$
\rho=R \frac{A}{L}
$$

dimana $\quad \rho$ adalah tahanan jenis material, $R$ adalah tahanan yang diukur, $L$ adalah panjang penampang dan $A$ adalah luas penampangnya. Jika persamaan 1 dimasukkan ke persamaan 2 maka akan diperoleh persamaan 3 .

$$
\rho=\frac{\Delta V}{I} \cdot \frac{A}{L}
$$

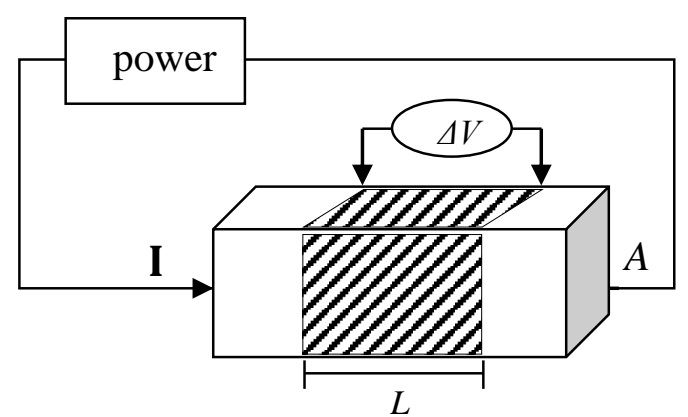

Gambar 3. Contoh medium yang dialiri arus listrik ${ }^{[9]}$.

Akuisisi data metode tahanan jenis menggunakan konfigurasi elektroda dipoledipole (Gambar 4). Penggunaan konfigurasi elektroda dipole-dipole dapat memetakan bawah permukaan secara dua dimensi, yaitu lateral dan sounding secara bersamaan ${ }^{[10]}$. Pengukuran dengan konfigurasi ini akan menghasilkan data dalam bentuk penampang kedalaman semu atau biasa disebut juga penampang semu. Posisi elektroda arus $\mathrm{C}_{1} \mathrm{C}_{2}$ diletakkan pada jarak $a$, sedang elektroda potensial $\quad \mathrm{P}_{1} \mathrm{P}_{2}$ juga berjarak $a$ yang diletakkan di luar elektroda arus dalam satu garis survei. Jarak $\mathrm{C}_{2}-\mathrm{P}_{1}$ sebesar na, dimana $\mathrm{n}=1,2,3,4,5$, dan seterusnya.

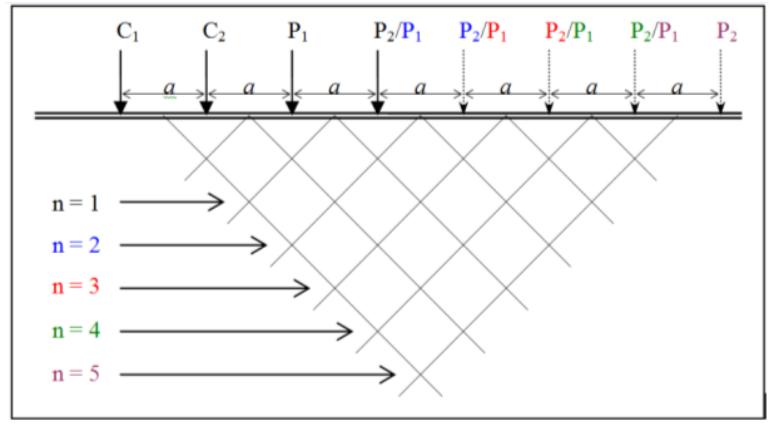

Gambar 4. Konfigurasi elektroda dipole-dipole yang menghasilkan data dalam bentuk penampang kedalaman semu.

\section{Metode Polarisasi Terinduksi}

Metode polarisasi terinduksi merupakan salah satu metode geofisika yang paling sesuai dalam eksplorasi mineral, merupakan satu-satunya metode yang responsif terhadap penyebaran mineralisasi dengan kadar yang rendah $^{[11]}$. Metode polarisasi terinduksi mengukur adanya polarisasi di dalam medium karena pengaruh arus listrik yang melewatinya. Polarisasi banyak terjadi pada medium yang mengandung mineral logam (misalnya senyawa sulfida logam) sehingga metode ini lebih banyak dipakai untuk eksplorasi mineral logam.

Bentuk energi yang tersimpan pada medium dapat berupa energi mekanik dan energi kimia. Penyimpanan energi kimia ini dapat disebabkan oleh variasi mobilitas ion dalam fluida yang terkandung dalam medium (efek pertama) dan variasi antara konduktivitas elektrolit dan elektron dalam medium yang mengandung mineral logam (efek kedua). Akibat efek pertama menghasilkan polarisasi membran atau polarisasi elektrolit dan merupakan efek dasar atau disebut juga efek normal dari polarisasi terinduksi. Kondisi ini terjadi pada batuan yang tidak mengandung mineral-mineral logam. Akibat efek kedua dikenal dengan polarisasi elektroda atau overvoltage. Efek 
polarisasi elektroda biasanya lebih besar dari efek polarisasi membran. Besar efek polarisasi elektroda tergantung pada kandungan mineral logam yang ada dalam batuan $^{[9]}$.

Akuisisi data dilakukan dalam domain frekuensi. Teknik pengukuran domain frekuensi melibatkan pengukuran tahanan jenis semu (apparent resistivity) pada dua atau lebih frekuensi arus bolak balik. Akuisisi data di lapangan bersamaan dengan metode tahanan jenis, yaitu menggunakan konfigurasi elektroda dipole-dipole. Teknis pengambilan datanya sama dengan metode tahanan jenis.

Gambar 5 menunjukkan hubungan tahanan jenis semu dengan log frekuensi arus dengan 3 daerah semu ${ }^{[12]}$. Daerah 1 berada dalam frekuensi rendah dimana tahanan jenisnya bersifat independen terhadap frekuensi. Daerah 2 adalah daerah Warberg, dimana tahanan jenisnya merupakan sebuah fungsi linear dari log frekuensi. Sedangkan daerah 3 adalah daerah induksi elektromagnetik, dimana aliran arus mengalami induksi. Karena hubungan yang diilustrasikan pada Gambar 5 bervariasi terhadap tipe batuan dan konsentrasi mineral, pengukuran polarisasi terinduksi biasanya dibuat pada atau di bawah frekuensi $10 \mathrm{~Hz}$ agar tetap dalam daerah non induksi. Pada eksplorasi yang lebih dalam, dipole dan separasinya harus besar, dan frekuensi pengoperasiannya biasanya rendah dengan tujuan untuk menghindari efek kopling dengan gelombang elektromagnet ${ }^{[13]}$. Oleh karena itu, akuisisi data yang dilakukan menggunakan arus listrik dengan frekuensi $0,3 \mathrm{~Hz}$ untuk frekuensi rendah dan $3,0 \mathrm{~Hz}$ untuk frekuensi tingginya.

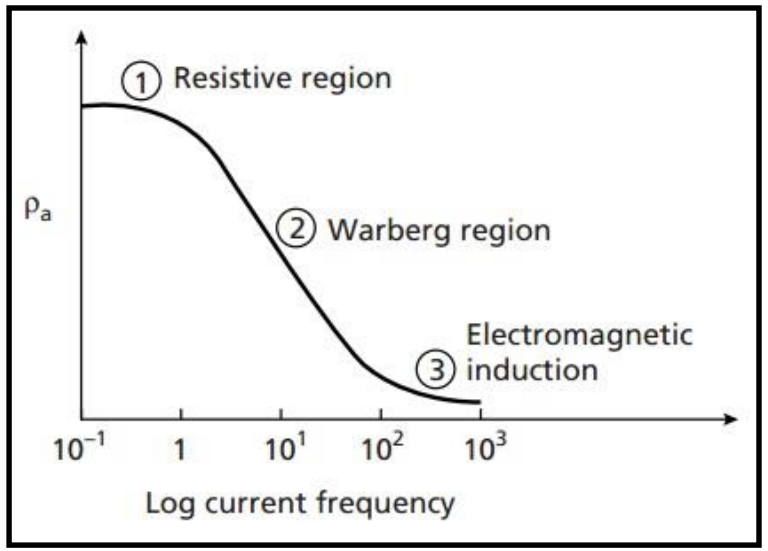

Gambar 5. Grafik hubungan antara tahanan jenis semu dengan log frekuensi arus ${ }^{[12]}$.

Proses elektrokimia pada medium yang banyak terjadi polarisasi berlangsung lambat. Pemberian arus pada frekuensi rendah menimbulkan polarisasi yang lebih besar jika dibandingkan dengan pemberian arus dengan frekuensi tinggi. Apabila arus bolak-balik dengan frekuensi rendah dimasukkan ke dalam medium yang banyak terjadi polarisasi maka potensial yang terukur bernilai tinggi. Hal ini mencerminkan nilai tahanan jenis yang tinggi. Sebaliknya polarisasi belum terjadi bila pemberian arus listrik searah hanya sebentar kemudian dibalik arahnya, atau dengan kata lain pemberian arus bolakbalik dengan frekuensi tinggi. Hal ini menyebabkan nilai potensial yang terukur lebih rendah sehingga mencerminkan nilai tahanan jenis pada frekuensi tinggi lebih rendah.

Paramater yang dihitung adalah percent frequency effect (PFE) dan faktor logam atau metal factor $(M F)^{[9]}$ :

$$
P F E=\frac{\rho_{d c}-\rho_{a c}}{\rho_{a c}} \times 100
$$

dengan $\rho_{d c}$ adalah tahanan jenis yang terukur pada frekuensi rendah dan $\rho_{a c}$ adalah tahanan jenis yang terukur pada frekuensi tinggi. 


$$
\begin{aligned}
M F & =\left(\frac{\left(\rho_{d c}-\rho_{a c}\right)}{\rho_{d c} \rho_{a c}}\right) \times 2 \pi \times 10^{5} \\
& =\frac{P F E}{\rho_{d c}} \times 2 \pi \times 1000
\end{aligned}
$$

\section{METODOLOGI}

Pengambilan data tahanan jenis dan polarisasi terinduksi dilakukan tahun 1985 dengan jarak antar titik pengukuran adalah 25 meter. Jumlah lintasan pengukuran adalah 46 lintasan. Panjang lintasan 425 meter dan jarak antar lintasan 25 meter. Jarak pemisahan maksimum pasangan elektroda potensial yang digunakan adalah 125 meter $(\mathrm{n}=5)$. Pengukuran dilakukan dengan arah utaraselatan. Data tahanan jenis hasil pengukuran dihitung dengan mempertimbangkan faktor geometrinya (Gambar 6).

Model inversi 2-D dilakukan pada data tahanan jenis dan polarisasi terinduksi menggunakan program komputer untuk mencitrakan kondisi bawah permukaan ${ }^{[14]}$. Model yang dihasilkan berupa penampang 2 dimensi dengan lintasan berarah utara-selatan dan kedalaman. Pengolahan data tahanan jenis semu akan menghasilkan model 2 dimensi tahanan jenis sebenarnya hasil inversi. Pengolahan data faktor logam hasil pengukuran akan menghasilkan model 2 dimensi faktor logam hasil inversi. Data hasil inversi ini kemudian disatukan sehingga diperoleh peta kontur tahanan jenis dan faktor logam pada kedalaman tertentu.

Nilai tahanan jenis dan faktor logam pada tubuh mineral sulfida ditentukan dengan melakukan korelasi antara data sumur yang tersedia dengan nilai tahanan jenis dan faktor logam hasil inversi. Hasil korelasi ini digunakan sebagai acuan dalam menentukan distribusi deposit uranium di seluruh daerah penelitian.

\section{HASIL DAN PEMBAHASAN}

Data tahanan jenis dan faktor logam diperoleh dari proses inversi data. Korelasi dengan sumur bor dilakukan terhadap data tahanan jenis dan faktor logam hasil inversi. Korelasi lintasan RT dengan sumur RDH-3 dapat dilihat pada Gambar 7 dan 8. Korelasi difokuskan pada kedalaman yang terdapat mineralisasi sulfida. Keberadaan sulfida ini mencerminkan keberadaan deposit uranium. Nilai tahanan jenis dan faktor logam yang diperoleh dari korelasi kemudian digunakan sebagai acuan dalam menentukan tubuh mineralisasi di daerah penelitian.

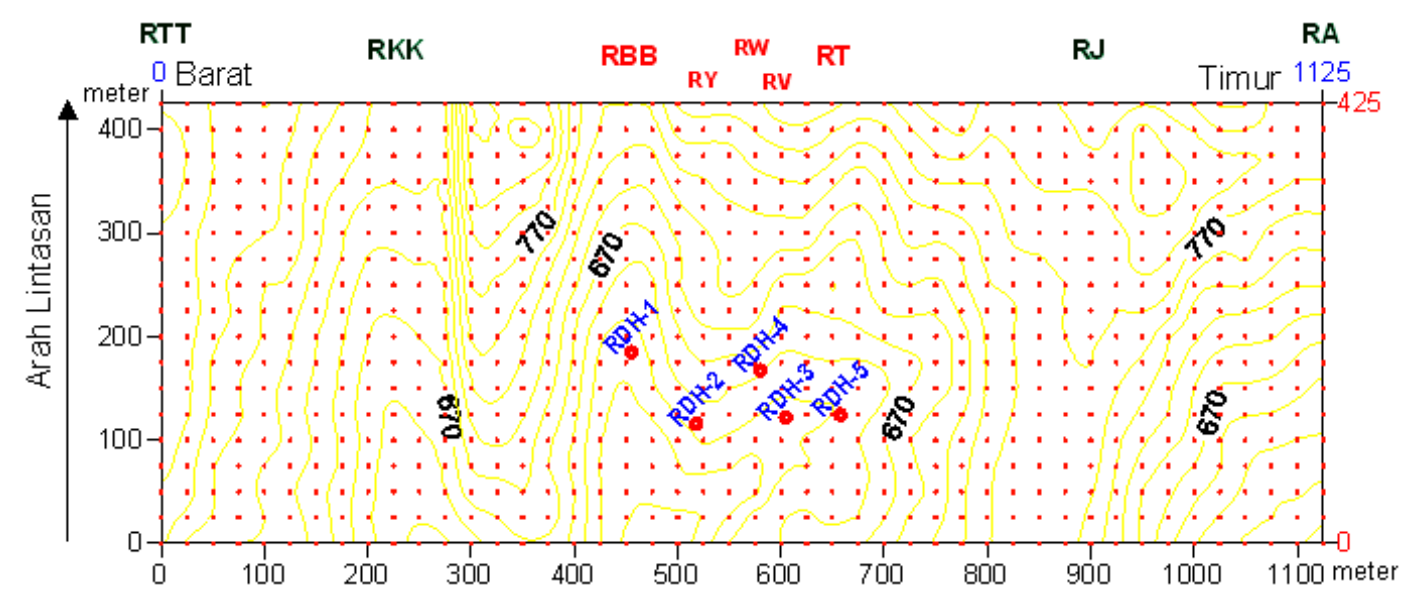

Gambar 6. Titik-titik pengukuran tahanan jenis dan polarisasi terinduksi dengan lintasan berarah utara-selatan di daerah Rabau Hulu, Kalan, Kalimantan Barat. 
Nilai tahanan jenis dan faktor logam zona deposit uranium merupakan hasil korelasi antara data hasil pengolahan dengan data sumur bor (Tabel 1). Asumsi awal bahwa tubuh deposit uranium memiliki nilai tahanan jenis yang relatif rendah dan faktor logam relatif lebih tinggi jika dibandingkan batuan di sekitarnya. Hal ini akibat adanya mineral sulfida yang bersifat konduktif yang berasosiasi dengan mineral uranium.

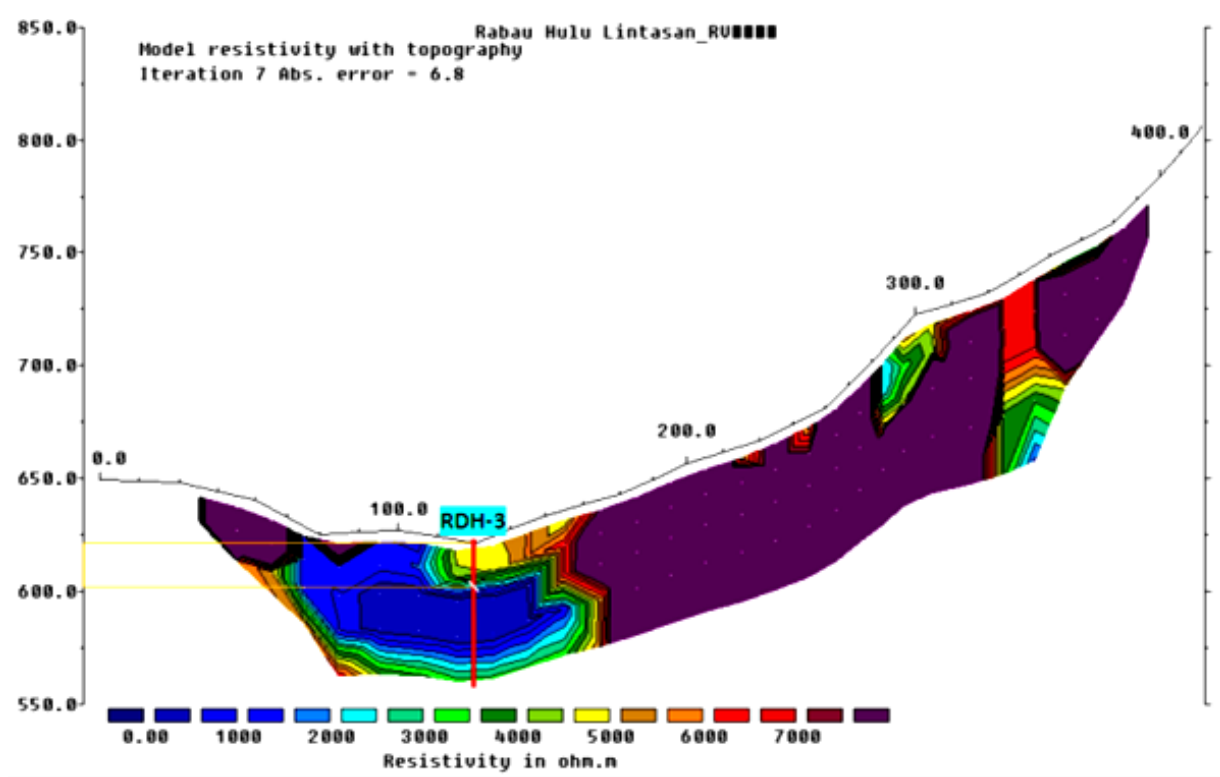

Gambar 7. Korelasi antara sumur RDH-3 dengan nilai tahanan jenis pada penampang 2 dimensi lintasan RV.

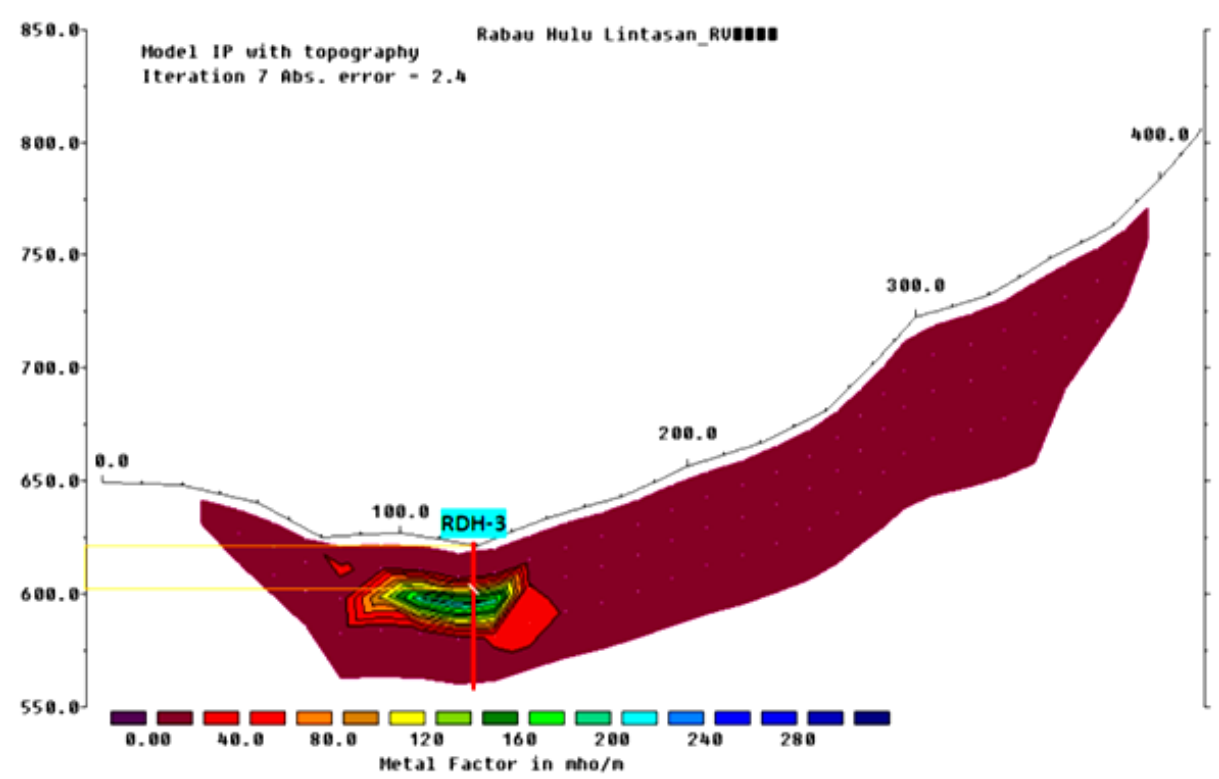

Gambar 8. Korelasi antara sumur RDH-3 dengan nilai faktor logam pada penampang 2 dimensi lintasan RV. 
Tabel 1. Nilai tahanan jenis dan faktor logam mineralisasi sulfida yang diperoleh dari korelasi antara sumur dengan nilai tahanan jenis dan faktor logam pada penampang 2 dimensi lintasan pengukuran.

\begin{tabular}{cccccccc}
\hline & \multicolumn{4}{c}{ Sumur Bor } & \multicolumn{3}{c}{ Mineralisasi Sulfida } \\
\cline { 2 - 7 } No. & $\begin{array}{c}\text { Titik } \\
\text { Bor }\end{array}$ & Elevasi & Azimuth & Inklinasi & Kedalaman & $\begin{array}{c}\text { Tahanan Jenis } \\
\text { Maksimum }(\Omega m)\end{array}$ & $\begin{array}{c}\text { Faktor Logam } \\
\text { Minimum (mho/m) }\end{array}$ \\
\hline 1 & RDH-2 & 639,21 & 180 & 90 & 32,75 & 1.500 & 90 \\
2 & RDH-3 & 617,34 & 180 & 90 & 19,15 & 2.000 & 90 \\
3 & RDH-4 & 658,06 & 180 & 90 & 43,75 & 2.000 & 90 \\
4 & RDH-5 & 637,50 & 180 & 90 & 38,65 & 500 & 90 \\
\hline
\end{tabular}

Tabel 1 menunjukkan bahwa zona mineralisasi memiliki tahanan jenis relatif rendah. Nilai tahanan jenis yang digunakan sebagai acuan zona mineralisasi maksimal $2.000 \Omega \mathrm{m}$. Nilai acuan faktor logam yang digunakan adalah $90 \mathrm{mho} / \mathrm{m}$ yang merupakan nilai mayoritas pada zona mineralisasi hasil korelasi. Zona mineralisasi di daerah Rabau Hulu memiliki nilai tahanan jenis maksimum $2.000 \Omega \mathrm{m}$ dan faktor logam minimum 90 $\mathrm{mho} / \mathrm{m}$. Kedua syarat tersebut harus dipenuhi dalam penentuan distribusi mineralisasi uranium di daerah Rabau Hulu.

Data tahanan jenis sebenarnya diperoleh dari proses inversi data tahanan jenis semu. Hasil inversi ini berupa titik-titik pada kedalaman tertentu dengan nilai tahanan jenis yang berbeda-beda. Jika keseluruhan titik pada kedalaman yang sama dengan koordinat tertentu dalam area penelitian maka akan terbentuk peta kontur tahanan jenis pada kedalaman tersebut (Gambar 9). Kedalaman yang digunakan menyesuaikan dengan hasil keluaran dari inversi yaitu $5,20 \mathrm{~m}, 16,9 \mathrm{~m}$, $31,5 \mathrm{~m}, 49,8 \mathrm{~m}$, dan $72,7 \mathrm{~m}$. Nilai tahanan jenis permukaan diwakili oleh kontur dengan kedalaman 5,20 m.

Kontur nilai tahanan jenis pada Gambar 9 menunjukkan adanya batuan dengan tahanan jenis kurang dari $2.000 \Omega \mathrm{m}$ semakin meluas ke arah kedalaman. Terdapat tiga zona dengan tahanan jenis rendah. Zona ini mewakili batuan favourable yang kemungkinan besar terdapat mineralisasi uranium yang berasosiasi dengan sulfida. Sebagian besar mineralisasi uranium kemungkinan berada di bagian selatan dan timur daerah penelitian.

Data faktor logam diperoleh dari proses inversi data faktor logam hasil pengukuran. Hasil inversi ini berupa titik-titik pada kedalaman tertentu dengan nilai faktor logam yang berbeda-beda. Peta kontur faktor logam yang menggambarkan titik-titik dengan nilai yang sama ditunjukkan oleh Gambar 10. Kedalaman yang digunakan menyesuaikan dengan hasil keluaran dari inversi yaitu 5,20 m, 16,9 m, 31,5 m, 49,8 m, dan 72,7 m.

Kontur nilai faktor logam pada Gambar 10 menunjukkan adanya batuan dengan faktor logam lebih dari $90 \mathrm{mho} / \mathrm{m}$ yang semakin meluas ke arah kedalaman. Terdapat dua zona utama dengan nilai faktor logam lebih dari 90 $\mathrm{mho} / \mathrm{m}$. Nilai faktor logam tersebut menunjukkan kemungkinan terdapatnya mineralisasi uranium yang berasosiasi dengan sulfida. Sebagian besar mineralisasi uranium kemungkinan besar berada di bagian selatan dan timur daerah penelitian, sedangkan bagian utara tidak menunjukkan adanya indikasi mineralisasi uranium. 


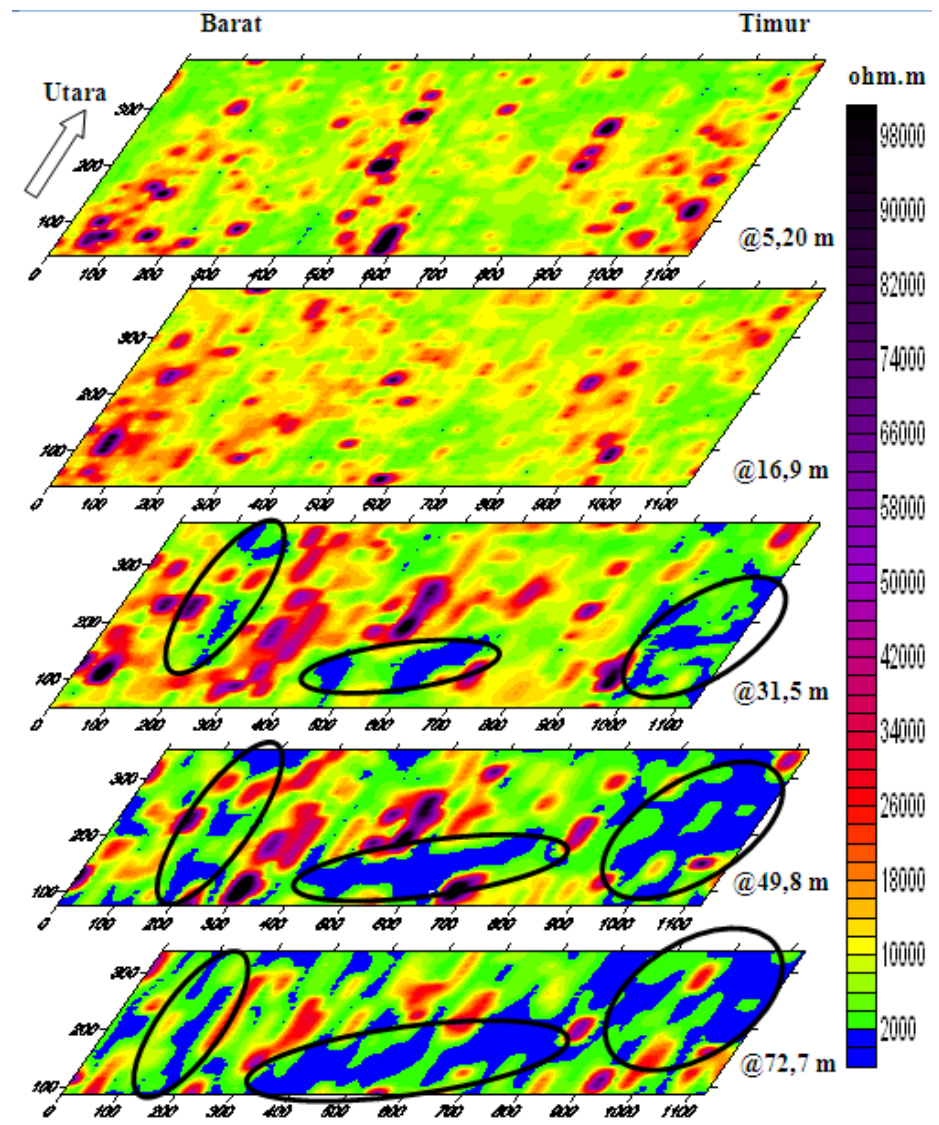

Gambar 9. Peta kontur tahanan jenis pada kedalaman $n=1$ sampai $n=5$ di daerah Rabau Hulu.

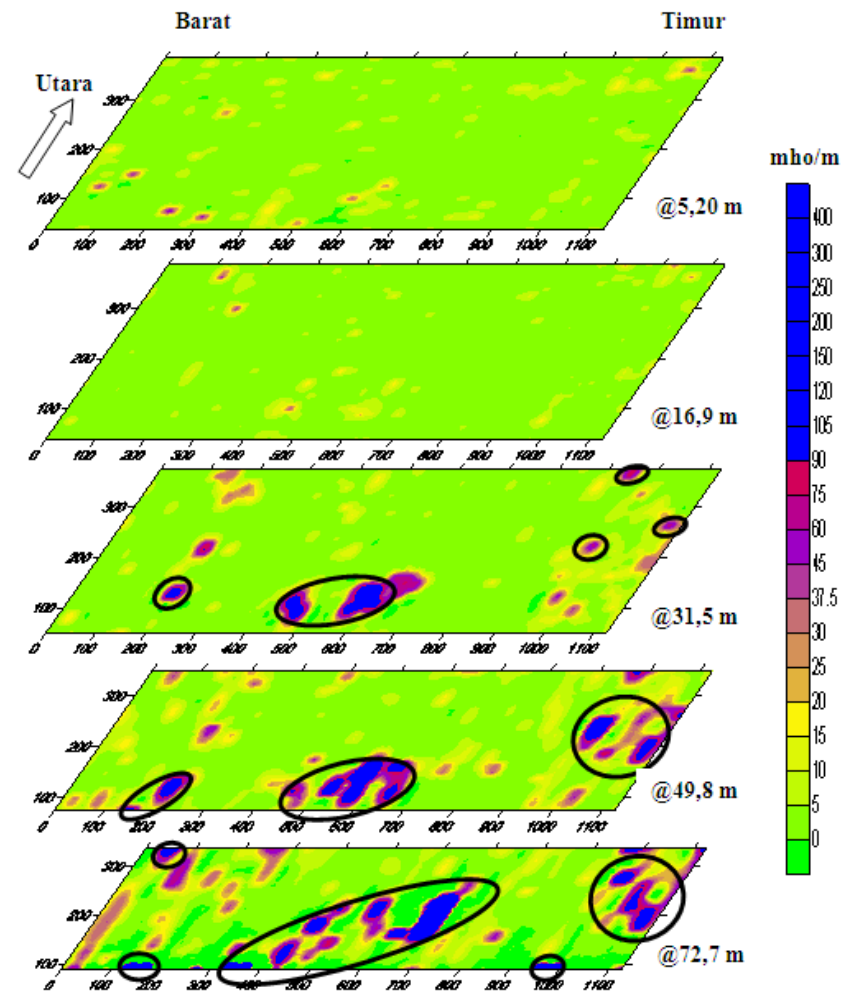

Gambar 10. Peta kontur faktor logam pada kedalaman $n=1$ sampai $n=5$ di daerah Rabau Hulu. 


\section{KESIMPULAN}

Zona deposit uranium berada pada batuan dengan nilai tahanan jenis kurang dari 2.000 $\Omega \mathrm{m}$ dan nilai faktor logam lebih dari 90 $\mathrm{mho} / \mathrm{m}$. Nilai ini diperoleh dari korelasi data sumur dengan data tahanan jenis dan faktor logam hasil inversi. Zona deposit uranium mayoritas berada di bagian selatan dan timur dalam daerah penelitian dengan bentuk yang semakin membesar seiring dengan kedalaman. Keberadaan deposit uranium umumnya saling terpisah satu dengan lainnya. Distribusi deposit berarah barat daya-timur laut. Hasil pengolahan kembali ini dapat memberikan gambaran bawah permukaan yang lebih jelas dan lebih baik jika dibandingkan dengan hasil pengolahan sebelumnya yang masih dilakukan secara manual.

\section{UCAPAN TERIMA KASIH}

Penulis mengucapkan terima kasih kepada Geofisika Reservoar UI atas segala masukan dan ilmu yang diberikan yang sangat mendukung penulisan naskah ini dan rekan kerja di PTBGN-BATAN atas segala masukan dan bantuannya.

\section{REFERENSI}

1. INTERNATIONAL ATOMIC ENERGY AGENCY (IAEA), "Analysis of Uranium Supply to 2050”, Vienna, 2001.

2. NGADENIN, SOETARNO, D., TJOKROKARDONO, S., WITJAHYATI, R., SUBIANTORO, L., WIDODO, M., SOETOPO, B., WUSANA, Y., RUSMADI, HANDOKO, SUJIMAN, dan PAIMIN, "Sintesis Geologi dan Mineralisasi Uranium Cekungan Kalan, Kalimantan Barat, Kapita Selekta Sintesis Geologi dan Mineralisasi Uranium Kalan dan Sekitarnya", Laporan Internal PPBGGN-BATAN, 2005.

3. IRAWAN, I., "Laporan Penyelidikan Metode Polarisasi Terimbas dan Magnetik di Daerah Jeronang Hulu dan Rabau Hulu, Kalimantan Barat", PT. ANTAM Unit Geologi, Jakarta, 1985.

4. SOETOPO, B., WITJAHYATI, R., dan WUSANA, Y., "Sintesis Geologi dan Mineralisasi Uranium Sektor Rabau Hulu, Kalimantan Barat", Eksplorium, 25, 13, P2BGGN-BATAN, Jakarta, 2004.

5. BATAN-CEA, "Prospect to Develop Uranium Deposits in Kalimantan Volume I and II, Introduction General Reconnaissance", 1977.

6. SASTRATENAYA, A.S., DWIYONO, WIDODO, M., dan DJALIL, A., "Laporan Akhir Prospeksi Super Detail Sektor Rabau Hulu Kalimantan Barat", Laporan internal P2BGN-BATAN, Jakarta, 1995.

7. YUVAL and OLDENBURG, D.W., "DC Resistivity and IP methods in Acid Mine Drainage Problems: Results from the Copper Cliff Mine Tailings Impoundments", Journal of Applied Geophysic, 34, 187-198, 1996.

8. LOWRIE, W., "Fundamental of Geophysics ( $2^{\text {nd }}$ ed.)”, New York: Cambridge University Press, 2007.

9. TELFORD, W.M., GELDART, L. P., SHERRIF, R.E., and KEYS, D. A., "Applied Geophysics (2 $2^{\text {nd }} \quad$ ed.)", Cambridge University Press, Cambridge, London, New York, Melbourne, 1990.

10. INSANI, A.R. dan YULIANTO, T., "Interpretasi Struktur Bawah Permukaan Daerah Manifestasi Mineral Emas Sistem Epithermal dengan Metode Polarisasi Terimbas (Induced Polarization) di Daerah "X" Kabupaten Garut Jawa 
Barat", Youngster Physics Journal, 3-4, 13. GHORBANI, A., CAMERLYNCK, C., 285-290, Oktober 2014. and FLORSCH, N., "CR1Dinv: A Matlab

11. MILSOM, J., "Field Geophysics ( $3^{\text {rd }}$ ed.) Program to Invert 1D Spectral Induced - The Geological Field Guide Series”, John Willey \& Sons Ltd. England, 2003.

12. KEAREY, P., BROOKS, M., and HILL, I., "An Introduction to Geophysical Exploration ( $3^{\text {rd }}$ ed.)", Blackwell Science Ltd. London, 2002. Polarization Data for the Cole-Cole Model Including Electromagnetic Effects", Journal of Computers and Geosciences, 35, 255-266, 2009.

14. LOKE, M.H., "Tutorial: 2-D and 3-D Electrical Imaging Surveys", Geotomo Software, Penang-Malaysia, 2004. 